\title{
Correction to: Prolonged stable disease in a uveal melanoma patient with germline MBD4 nonsense mutation treated with pembrolizumab and ipilimumab
}

Peter A. Johansson ${ }^{1}$ (D) $\cdot$ Andrew Stark $^{2} \cdot$ Jane M. Palmer $^{1} \cdot$ Kieron Bigby $^{3,4,5} \cdot$ Kelly Brooks $^{1} \cdot$ Olivia Rolfe $^{2}$. Antonia L. Pritchard ${ }^{1,6} \cdot$ Kevin Whitehead $^{7} \cdot$ Sunil Warrier ${ }^{2} \cdot$ William Glasson $^{2} \cdot$ Nicholas K. Hayward $^{1}$

(C) Springer-Verlag GmbH Germany, part of Springer Nature 2019

Correction to: Immunogenetics (2019) 71:433-436

https://doi.org/10.1007/s00251-019-01108-x

The authors regret that the online version of this article contains an error. The MBD4 mutation in sample MM138 was given an incorrect dbSNP ID. The correct ID is rs769076971.

Publisher's note Springer Nature remains neutral with regard to jurisdictional claims in published maps and institutional affiliations.

The online version of the original article can be found at https://oi.org/ 10.1007/s00251-019-01108-x

Peter A. Johansson

peter.johansson@qimrberghofer.edu.au

1 QIMR Berghofer Medical Research Institute, Brisbane, QLD 4006, Australia

2 Queensland Ocular Oncology Service, The Terrace Eye Centre, Brisbane, QLD, Australia

3 Montserrat Cancer Care, North Lakes Day Hospital, North Lakes, QLD, Australia

4 Redcliffe Hospital, Anzac Ave, Redcliffe, QLD, Australia

5 School of Medicine, University of Queensland, St Lucia, QLD, Australia

6 The University of the Highlands and Islands, Inverness, UK

7 Sullivan Nicolaides Pathology, Brisbane, QLD, Australia 